\title{
A influência de uma ação de inclusão no interesse das alunas de ensino médio em cursar Computação na Universidade Federal de Goiás
}

\author{
Talita Atahalpa R. Ferreira ${ }^{1}$, Elisângela Silva Dias ${ }^{1}$ \\ ${ }^{1}$ Instituto de Informática - Universidade Federal de Goiás (UFG) \\ Alameda Palmeiras, Câmpus Samambaia - 74690-900 - Goiânia - GO - Brasil \\ tf-tarfegmail.com, elisangelaeinf.ufg.br
}

\begin{abstract}
While women have pioneered computing, the interest of female high school students in computing and female participation in the academic and professional computing environment has been declining over time. In this article, we show the results of the research carried out with female high school students during an inclusion action designed to increase the visibility of women who were part of the history of Computing and to encourage female participation in Computing. It was concluded that the inclusion action positively influenced interest in Computing by female high school students participating in the research.
\end{abstract}

Resumo. Embora as mulheres tenham sido pioneiras na Computação, o interesse de alunas do ensino médio em Computação e a participação feminina no ambiente acadêmico e profissional da Computação vem diminuindo ao longo do tempo. Neste artigo, mostramos os resultados da pesquisa realizada com alunas do ensino médio durante uma ação de inclusão destinada a aumentar a visibilidade das mulheres que fizeram parte da história da Computação e incentivar a participação feminina na Computação. Concluímos que a ação de inclusão influenciou positivamente no interesse em Computação por parte das alunas do ensino médio participantes da pesquisa.

\section{Introdução}

Segundo o relatório da UNESCO [UNESCO 2018], apenas 35\% das mulheres estão na universidade em cursos de STEM Science, Technology, Engineering, and Mathematics em todo o mundo. O relatório expõe que meninos e meninas possuem o mesmo interesse e habilidades em STEM até a educação básica e que o interesse diminui consideravelmente na adolescência. Estereótipos de gênero, fatores socioeconômicos e culturais são os principais responsáveis pelo distanciamento de meninas e mulheres da STEM [Cheryan et al. 2015]. Para Scheckler [Scheckler 2008] pesquisas e iniciativas a nível institucional são primordiais para o aumento de mulheres na Computação, uma área que, segundo a autora, ainda reluta em assumir que exista um problema de gênero. No Brasil, apenas $14 \%$ de todos os matriculados em Computação no Brasil é do sexo feminino [Nunes 2018]. Na UFG, no ano de 2018, apenas 9,3\% dos ingressantes eram do sexo feminino [INF 2018].

O Instituto de Informática (INF) da UFG criou, em 2017, o Projeto ADAs que visa a inclusão de meninas e mulheres na Computação. Em 2018, o Projeto ADAs realizou uma ação de inclusão para aumentar a visibilidade das mulheres que fizeram parte da 
história da Computação e influenciar no interesse de alunas do ensino médio em ingressar em uma graduação em Computação na UFG. A ação ocorreu durante o Espaço das Profissões, uma exposição que aproxima os universitários e profissionais da Instituição de estudantes do ensino médio e estimou-se a participação de 40 mil discentes do ensino médio da capital e do interior do estado nos dois dias de evento, ocorridos nas dependências do Campus II da UFG [UFG 2018]. Na próxima Seção apresentamos a motivação e trabalhos relacionados, na 3 detalhes da ação de inclusão e da pesquisa, na 4 análise dos resultados e por fim as considerações finais na Seção 5.

\section{Motivação}

Esta pesquisa foi motivada pela necessidade de analisar a visão de meninas e mulheres do ensino médio em relação à Computação, e analisar o impacto da ação de inclusão no interesse destas em cursar Computação na UFG. Aproveitamos o grande quantitativo de alunos de ensino médio visitando o Espaço das Profissões e a Ação promovida pelo INF. Os trabalhos de Bim e Sardiña [Bim et al. 2016, Sardiña and Maciel 2016] mostram ações que visam a diversificar a participação, atraindo mais mulheres para área, porém estes levaram a ação até as alunas em suas respectivas escolas.

\section{Ação de inclusão e Passaporte}

A ação teve como tema "Mulheres na Computação" e organizou três salas temáticas, na Sala Interativa - Carol Shaw, os visitantes puderam interagir com o que foi apresentado, como jogos, realidade aumentada, realidade virtual, entre outros. A Sala Proativa - Ada Lovelace continha cartazes, pôsteres e vídeos sobre os projetos de extensão e pesquisa desenvolvidos pelos cursos de Computação da UFG, e da trajetória de mulheres na Computação. Por fim, a Sala Informativa - Grace Hopper os visitantes obtinham informações detalhadas sobre cada curso ofertado pelo Instituto de Informática da UFG.

Para aumentar a participação na ação e na pesquisa formulamos o passaporte conforme mostra a Figura 1, sendo composta por três imagens de figuras femininas importantes na história da Computação, Grace Hopper, Carol Shaw e Ada Lovelace, representando cada uma das salas respectivamente. Cada aluna que visitou as salas recebeu um passaporte e foi informada da necessidade de carimbar a visita em cada sala, para isto as alunas teriam que participar de ao menos uma das atividades propostas, e de responder a pesquisa constante no verso. Desta forma, cada aluna que cumpriu as orientações e entregou o passaporte preenchido, com todos os carimbos, recebeu um brinde como recompensa à participação. Formulamos um questionário curto pois, na dinâmica do Espaço das Profissões o tempo de visita por sala era curto, tornando difícil manter as participantes engajadas por muito tempo. A Tabela 1 lista as perguntas contidas no questionário.

\section{Análise dos resultados}

Foram coletados 55 questionários no primeiro dia do Espaço das Profissões e 62 no segundo, totalizando 117 questionários recebidos, dos quais um destes foi desconsiderado, pois apresentou respostas incongruentes. Preenchidos à mão, as respostas do questionário foram tabuladas em uma planilha. Pelas perguntas 1 e 2 , observamos que houve uma maior participação por parte de alunas entre 16 e 20 anos provenientes de escolas públicas nos últimos anos do ensino médio, por este motivo a maioria das alunas já haviam decidido por suas graduações antes de visitar o Espaço das Profissões. 


\section{Passaporte}

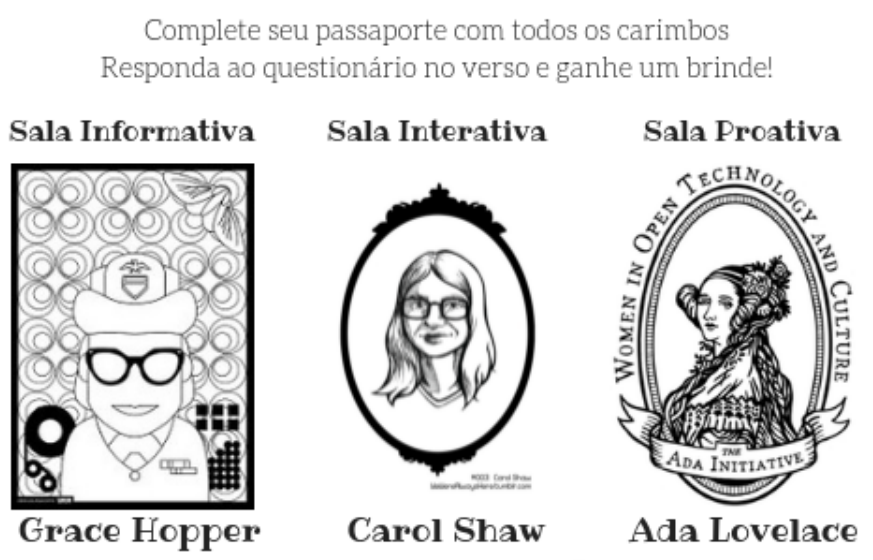

Figura 1. Frente do Passaporte.

Pelas perguntas 3 e 4 analisamos o interesse das participantes em cursar Computação antes e depois da visita ao Espaço das Profissões. Podemos observar na Figura 2, que "Antes" 26\% das alunas informaram que "jamais" considerariam cursar Computação, e 40\% "talvez". Vemos também pela Figura 2 que apenas $7 \%$ informaram que "jamais" cursariam Computação "Após" visitar o Espaço das Profissões.

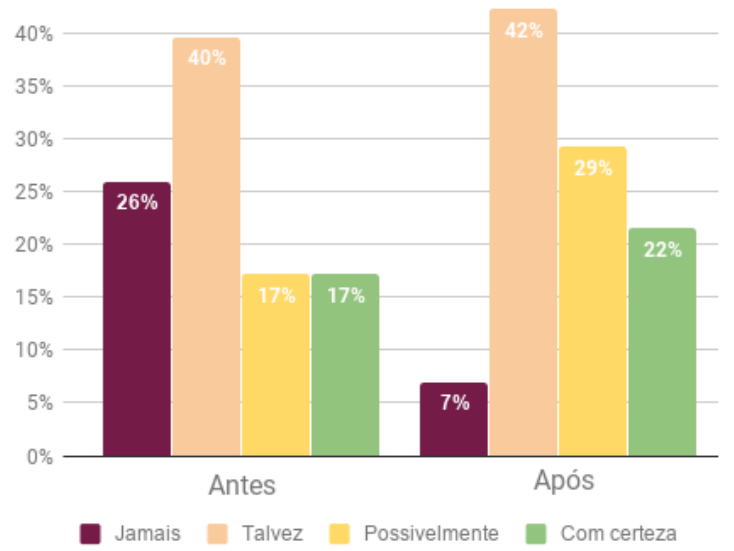

Figura 2. Interesse das participantes antes e após a participação da ação de inclusão.

Em resposta à pergunta $5,40 \%$ das alunas afirmaram que a falta de conhecimento na área, a dificuldade em gostar de Matemática e a sensação de que cursos na Computação são difíceis, foram os fatores preponderantes do não interesse destas em cursar Computação. Para Cheryan et al [Cheryan et al. 2015], os Estereótipos de gênero impõem uma barreiras para meninas e mulheres na Computação. Como meninas e mulheres desconhecem a área, é difícil medir o real interesse destas em ingressar na Computação, já que não podemos nos interessar por algo que nem temos ciência de sua existência. 
Tabela 1. Lista de perguntas contidas no questionário verso do Passaporte Espaço das Profissões.

\begin{tabular}{|c|c|c|}
\hline$\#$ & Pergunta & Opções \\
\hline 1 & Idade & \\
\hline 2 & Escola & Pública, Particular \\
\hline 3 & $\begin{array}{l}\text { Antes de Visitar o Espaço das Pro- } \\
\text { fissões, você cursaria um curso da } \\
\text { Computação? }\end{array}$ & $\begin{array}{l}\text { Jamais, Talvez, Possivelmente, } \\
\text { Com certeza }\end{array}$ \\
\hline 4 & $\begin{array}{l}\text { Após sua visita, você cursaria um } \\
\text { curso da Computação? }\end{array}$ & $\begin{array}{l}\text { Jamais, Talvez, Possivelmente, } \\
\text { Com certeza }\end{array}$ \\
\hline 5 & $\begin{array}{l}\text { Se você [jamais/talvez] cursaria um } \\
\text { curso de Computação, quais opções } \\
\text { te levaram a tomar essa decisão? }\end{array}$ & $\begin{array}{l}\text { Falta de Conhecimento na área, } \\
\text { Não gosto de Matemática, Não } \\
\text { gosto de Computador ou tecnolo- } \\
\text { gia, É um curso difícil, É um curso } \\
\text { mais apropriado para homens, Ou- } \\
\text { tro (especificar) }\end{array}$ \\
\hline 6 & $\begin{array}{l}\text { Você acha que a Computação é uma } \\
\text { área masculina? }\end{array}$ & Sim, Não \\
\hline 7 & Por quê? & \\
\hline 8 & Qual a sua sala favorita? & $\begin{array}{l}\text { Grace Hopper, Carol Shaw, Ada } \\
\text { Lovelace }\end{array}$ \\
\hline
\end{tabular}

Na pergunta $6,76,7 \%$ das participantes afirmaram que para elas a Computação não é uma área masculina e $19 \%$ das participantes afirmaram que sim. Na pergunta 7 , pedimos para que as alunas justificassem a resposta dada à pergunta 6. Recebemos 96 respostas em textos curtos e os separamos em dois grupos: Grupo Não e Grupo Sim.

Agrupados no Grupo Sim, respostas coerentes de participantes que afirmaram que a Computação é uma área masculina. Para este grupo, a Computação é uma área predominantemente masculina, onde preconceitos, machismo, Estereótipos de gênero e a baixa visibilidade de figuras femininas da área fazem com que a imagem passada da Computação seja mais apropriada para homens. Em uma das respostas a participante afirma que "a mulher na Computação sofre desigualdade porque nossa sociedade definiu a informática como profissão masculina", outra aluna afirmou: "Muitas mulheres não têm conhecimento que o curso de informática é um curso que abrange todos os gêneros onde a maioria tem medo de sofrer algum preconceito".

Para o Grupo Não, formado por participantes que afirmaram que a Computação não é masculina, a Computação é para toda e qualquer pessoa que tenha capacidade, independente do gênero. Respostas comuns foram: "Porque meninas também gostam"; "Porque mulheres são tão capazes quanto homens na área"; "Acredito que homens e mulheres têm a mesma capacidade de fazer". Outras alunas deste grupo justificaram que apesar de terem discordado que a Computação seja uma área masculina, acham que as mulheres não têm reconhecimento nem muita visibilidade na área. "Apesar de não achar creio que a mulher não possui tanto espaço nessa área", foi uma das respostas que recebemos deste grupo. 
Analisando ambos os grupos, afirmamos que a sensação geral de todas as participantes é que as mulheres têm capacidade para cursar Computação e atuar profissionalmente na área, onde que pessoas de qualquer sexo podem ser bem-sucedidas nos cursos e que a falta de conhecimento prévio da área afastam as mulheres da possibilidade de cursar Computação. As respostas da pergunta 8 indicaram que a sala favorita das participantes foi a Sala Interativa - Carol Shaw, com 37 votos, em segundo lugar, por apenas dois votos a menos, a Sala Informativa - Grace Hopper, analisamos que a interação e a informação instigou a participação das alunas na ação.

\section{Considerações finais}

Pelos dados apresentados afirmamos que a ação realizada no Espaço das Profissões influenciou no interesse de meninas e mulheres em Computação, porém não gerou um impacto real na escolha da graduação, pois estando nos últimos anos do ensino médio a maioria das participantes já vieram com objetivo de carreira predeterminada. Concluímos que ação gerou uma reflexão sobre o modo como as participantes vêm a Computação. Apesar da visão majoritária que a Computação não é masculina, as participantes demonstraram em suas respostas que ainda há muita desinformação e desvalorização das mulheres na área.

Propomos para trabalhos futuros uma ação de divulgação da participação feminina na Computação replicando em uma escala menor a ação executada no Espaço das Profissões para alunos do $8^{\mathrm{a}}$ ano do Ensino Fundamental no Centro de Ensino e Pesquisa Aplicada à Educação (CEPAE) da UFG.

\section{Referências}

Bim, S. A., Amaral, M. A., Kozievitch, N. P., Emer, M., Setti, M., Pellison, L., and Merkle, L. (2016). Divulgar para atrair, motivar para manter. $10^{\circ}$ WIT-Women in Information Technology, pages 2665-2669.

Cheryan, S., Master, A., and Meltzoff, A. N. (2015). Cultural stereotypes as gatekeepers: increasing girls interest in computer science and engineering by diversifying stereotypes. Frontiers in Psychology, 6:49.

INF (2018). Relatório de concluintes e ingressantes do Instituto de Informática da UFG de 2015 a 2018-1.

Nunes, D. (2018). Educação superior em computação, estatísticas 2017. Sociedade Brasileira de Computação-SBC.

Sardiña, I. and Maciel, C. (2016). Ações para incentivar meninas do ensino médio a cursar carreiras tecnológicas da universidade federal do rio grande do norte. In 10o Women in Information Technology (WIT 2016), Porto Alegre. In: Anais do XXXVI Congresso da Sociedade Brasileira de Computação (CSBC 2016).

Scheckler, R. K. (2008). Gender Myths and Beliefs in Computer Science, volume 1, pages 115-122. ABC-CLIO, Inc., Santa Barbara, California.

UFG (2018). Espaço das profissões aproxima UFG de estudantes do ensino médio.

UNESCO (2018). Decifrar o código: educação de meninas e mulheres em ciências, tecnologia, engenharia e matemática (STEM). Organização das Nações Unidas para a Educação, a Ciência e a Cultura. 